\title{
Zebularine regulates early stages of mESC differentiation: effect on cardiac commitment
}

\author{
A Horrillo ${ }^{1}$, D Pezzolla, ${ }^{1,2}$ MF Fraga ${ }^{3}$, Y Aguilera ${ }^{1}$, C Salguero-Aranda ${ }^{2,4}$, JR Tejedo ${ }^{2,4}$, F Martin ${ }^{2,4}$, FJ Bedoya ${ }^{2,4}$, B Soria ${ }^{1,2,5}$ \\ and $A$ Hmadcha*,1,2,5
}

Lineage commitment during embryonic stem cell (ESC) differentiation is controlled not only by a gamut of transcription factors but also by epigenetic events, mainly histone deacetylation and promoter DNA methylation. The DNA demethylation agent $5^{\prime}$-aza-2'-deoxycytidine (AzadC) has been widely described as an effective promoter of cardiomyogenic differentiation in various stem cell types. However, its toxicity and instability complicate its use. Therefore, the purpose of this study was to examine the effects of zebularine (1-( $\beta$-D-ribofuranosyl)-1,2-dihydropyrimidin-2-1), a stable and non-toxic DNA cytosine methylation inhibitor, on mouse ESC (mESC) differentiation. Herein, we report that treating embryoid bodies, generated from mESCs, with $30 \mu \mathrm{M}$ zebularine for 7 days led to greater cell differentiation and induced the expression of several cardiac-specific markers that were detected using reverse transcription-polymerase chain reaction (RT-PCR), real-time PCR, immunostaining and flow cytometry. Zebularine enhanced the expression of cardiac markers and the appearance of beating cells that responded to cardiac drugs, including ion channel blockers (diltiazem) and $\beta$-adrenergic stimulators (isoproterenol). Gene promoter methylation status was assessed using methylation-specific PCR (MSP) and validated by bisulfite sequencing analysis. Global gene expression profiling using microarrays showed that zebularine-differentiated cells are distinct from control ESCs. Pathway analysis revealed an enhancement of cellular processes such as embryonic development, cardiovascular system development and function. In addition, the whole-cell proteins exhibited different profiles as analyzed by two-dimensional differential-in-gel-electrophoresis. Our results indicate that zebularine regulates mesodermal differentiation of $\mathrm{mESCs}$, controls promoter methylation of crucial cardiac genes and may help to improve cardiomyogenic differentiation.

Cell Death and Disease (2013) 4, e570; doi:10.1038/cddis.2013.88; published online 4 April 2013

Subject Category: Experimental Medicine

Embryonic stem cells (ESCs) hold a great potential for cell replacement, despite a number of significant hurdles that still stand in the way of the realization of that potential. The most important among these are differentiation efficiency, safety concerns and overcoming immune rejection. ${ }^{1}$ Currently, ESCs and their resulting differentiated cell types provide a promising in vitro system for the study of early human embryonic development. ${ }^{2,3}$ As such, they can be used as cell lines with genetic disorders ${ }^{4,5}$ and are being used increasingly in drug screening. ${ }^{6,7}$

Differentiation of ESCs requires the repression of transcription factors involved in maintaining pluripotency and the activation of developmental genes. Both processes are directed by specific epigenetic mechanisms. An example of the first process is the promoter-methylation-dependent repression of Nanog and Oct3/4 as cells differentiate. ${ }^{8}$ Thus far, the activation of developmental genes during DNAdemethylation-induced stem cell differentiation has been less thoroughly studied. Instead, these developmental genes have been reported as being in a repressed state during the early stages of development because of the establishment of specific patterns of histone modifications, which consist of large regions of H3-Lys27 methylation harbouring smaller regions of H3-Lys4 methylation. ${ }^{9}$ This repressive chromatin state is mediated by the Polycomb group of proteins. ${ }^{10-12}$

Besides nitric oxide (NO) ${ }^{13}$ many epigenetic compounds efficiently invert genes' methylation status and histone

\footnotetext{
${ }^{1}$ Centro Andaluz de Biología Molecular y Medicina Regenerativa (CABIMER) - Fundación Progreso y Salud, Sevilla 41092, Spain; ${ }^{2}$ CIBER de Diabetes y Enfermedades Metabólicas Asociadas (CIBERDEM), Barcelona 08036, Spain; ${ }^{3}$ Department of Epigenetic, Oncologic Institute of Principado of Asturias, Oviedo 33006 , Spain and ${ }^{4}$ Centro Andaluz de Biología Molecular y Medicina Regenerativa (CABIMER) - University of Pablo de Olavide, Sevilla 41092, Spain

${ }^{*}$ Corresponding author: A Hmadcha, Department of Stem Cells, Andalusian Center for Molecular Biology and Regenerative Medicine (CABIMER), Avenida Americo Vespucio s/n Parque Científico y Tecnológico Cartuja 93, Sevilla 41092, Spain. Tel: + 34954468 373; Fax: + 34954 461 664; E-mail: karim.hmadcha@ cabimer.es ${ }^{5}$ These author share the senior authorship.

Keywords: embryonic stem cells; mesoderm; methylation; zebularine; AzadC; nitric oxide

Abbreviations: AzadC, $5^{\prime}$-aza-2'-deoxycytidine; DNMT, DNA methyltransferase; EBs, embryoid bodies; ESC, embryonic stem cell; GEO, gene expression omnibus; HDAC, histone deacetylase; hESC, human embryonic stem cell; HMT, histone methyltransferase; H3K4, histone H3 lysine 4; H3K9, histone H3 lysine 9; IPA, Ingenuity's Pathway Analysis; LIF, leukemia inhibitory factor; LIMMA, linear models for microarray; mESC, mouse embryonic stem cell; MSP, methylation-specific PCR; NO, nitric oxide; PI, propidium iodide; T-DMR, tissue-dependent and differentially methylated region; zebularine, 1-( $\beta$-D-ribofuranosyl)-1,2-dihydropyrimidin-2-1; 2D-DIGE, two-dimensional differential-in-gel-electrophoresis

Received 26.7.12; revised 13.1.13; accepted 21.2.13; Edited by Y Shi
} 
patterns; such compounds are currently in use for the treatment of cancer. ${ }^{14}$ Because treatment of ESCs with 5'-aza-2'-deoxycytidine (AzadC) initiates cardiac differentiation and gene reactivation, ${ }^{15,16}$ we tested the potential effect of zebularine (1-( $\beta$-D-ribofuranosyl)-1,2-dihydropyrimidin-2-1) on ESCs.

Zebularine is a cytidine analogue that is able to inhibit DNA methyltransferases (DNMTs) through covalent binding ${ }^{17-19}$ and is a robust inhibitor of cytidine deaminase, a central enzyme for the metabolism of cytosine nucleoside analogues such as $\mathrm{AzadC}^{20}$ which is increased in tumour cells as a resistance mechanism to antineoplastic drugs. Zebularine acts during DNA replication, substituting cytosine residues following its phosphorylation and conversion to deoxynucleotide. Once incorporated into DNA, it forms covalent complexes with DNMTs leading to inhibition of its activity, thereby decreasing DNA methylation. ${ }^{19}$ Overall, zebularine is a genome-wide demethylating agent with increased activity in proliferative cells.

Unlike AzadC, which is toxic in vitro and in vivo and is unstable in aqueous solution, zebularine is chemically stable in neutral and basic media. ${ }^{21,22}$ In addition, zebularine has a smaller myelosuppressive effect than AzadC; this leads to minimal side effects, making zebularine a candidate drug for long-term tumour treatment by oral administration. ${ }^{22}$

We tested the effect of zebularine on mouse ESCs (mESCs) and detected rhythmic and synchronized beating areas in embryoid bodies (EBs). We next studied the gene and protein expression of cardiac markers, finding that zebularine-treated cells highly expressed cardiac-restricted markers and expressed low levels of pluripotency factors. Moreover, when gene expression was compared between cells treated with zebularine, AzadC and NO, the cardiac expression patterns showed that zebularine preferentially drives the differentiation of mESCs towards a cardiomyocyte-like phenotype. These findings support the hypothesis that zebularine regulates mesodermal differentiation more efficiently than the other drugs tested. Next, we analyzed methylation gene promoter status and detected that Nkx2.5, an early marker of the cardiac lineage differentiation program, was clearly unmethylated and thus transcriptionally activated following zebularine treatment. To decipher the global effect of zebularine on gene expression, we performed microarray analysis and found a significant number of differentially expressed genes with a B-statistic $>1$, demonstrating that the cellular transcriptome is clearly modified following zebularine treatment. The differentially expressed genes were selected using a linear model approach $^{23}$ and implemented in the Linear Models for Microarray Bioconductor package and Ingenuity's Pathway Analysis (IPA) software. In addition, experiments having significant signatures or reverse/antisignatures were dissected using the entire mouse gene expression omnibus (GEO) experiments on the mouse Affymetrix platform deposited in the NCBI's GEO database. Moreover, proteins showed different patterns when subjected to two-dimensional differential-in-gel-electrophoresis (2D-DIGE). Finally, we studied the effect of zebularine on human ESCs (hESCs) and observed differences in the expression levels of some cardiac-specific genes after treatment.

\section{Results}

Zebularine preferably drives mESCs towards mesodermal lineage. On the basis of the previous results demonstrating that AzadC and NO were able to promote cardiac differentiation of ESCs, we tested and compared the effect of zebularine on mESCs in standard culture conditions (+LIF (leukemia inhibitory factor)). Using reverse transcription-polymerase chain reaction (RT-PCR), we compared gene expression after treatment with each of these three molecules. When AzadC or NO was used, we observed that pluripotency markers were expressed at levels similar to control samples, whereas cardiac-specific genes were slightly increased. The expression of Gata4, Actc, Myh6, Myh7, cTnT and Anf was higher in AzadC- and NO-treated cells than in control cells. In contrast, Serca2 was expressed similarly in all samples. The only difference detected was the expression of $\mathrm{CTnl}$ in NO addition and Hprt in AzadC treatment. Interestingly, when we compared gene expression in zebularine-, AzadC- and NO-treated cells, we observed that zebularine caused a reduction in the expression of the pluripotency markers Oct3/4, Nanog and FoxD3 than did AzadC or NO. Moreover, zebularinetreated cells demonstrated higher expression of genes, especially those expressed in cardiac tissues, such as Actc, Anf, cTnT, cTnl, Myh6 and Myh7. Serca2 was expressed at a level similar to the other samples (Figure 1a).

As widely known, EB-mediated differentiation is the most common method to induce spontaneous cardiac differentiation; however, the results of this differentiation have been fairly successful. Athough we postulated that zebularine could be considered a critical parameter for optimizing early in vitro mesodermal differentiation, we treated EBs with $30 \mu \mathrm{M}$ of zebularine, and then we assessed the gene expression at differentiating days 3, 5 and 7 for the three associated lineage markers (Figure 1b). We found that markers from different lineages are detected, interestingly, in zebularine-treated EBs, mesoderm markers (Brachyury, Gata4, Nkx2.5, $\alpha$ SMA, Desmin, Flk1, Hrt1, Mef2c BMP2, BMP4 and Noggin), which are markedly expressed starting at day 5; however, SM22 $\alpha$ and Serca2 are equally detected in all experimental conditions. Moreover both endoderm markers (Sox17, Pdx1, FoxA2, Sox7, Pax4, P48, Mist and Nkx6.1) and ectoderm markers (Wt1, Snail1, Slug, Otx2, Zic1, Nestin, Ngn, Pax6, Isl1 and Sox1) are less or not detected at differentiating days 3, 5 and 7 when compared with control EBs, and in addition, Oct4 and Nanog are slightly less detected in zebularine-treated EBs compared with control and ( - LIF). These results imply that zebularine is more efficient than AzadC or $\mathrm{NO}$ at promoting mesodermal gene expression.

Because of its lower toxicity, zebularine could potentially be used as a substitute for AzadC. To validate this hypothesis, we measured and compared Annexin- $V$ incorporation at differentiating days 3, 5 and 7 (Figure 1c) and found that apoptosis was significantly reduced in zebularine compared with AzadC, and even more at day 3, where significant increase of apoptosis occurs as for AzadC, thus confirming that zebularine has no cytotoxic effect on EBs. 
a

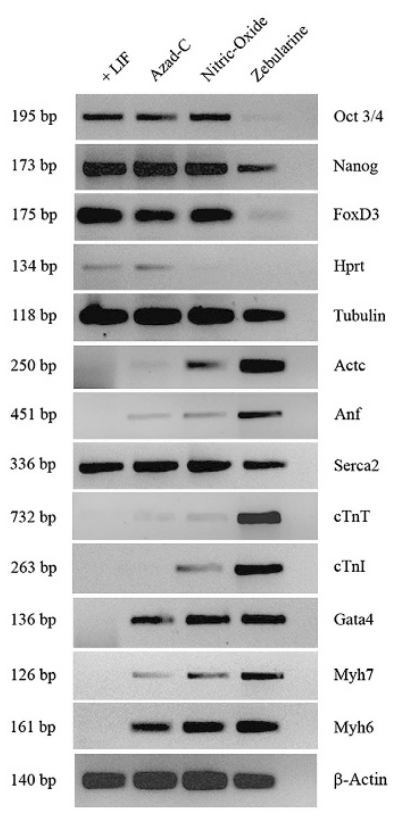

C

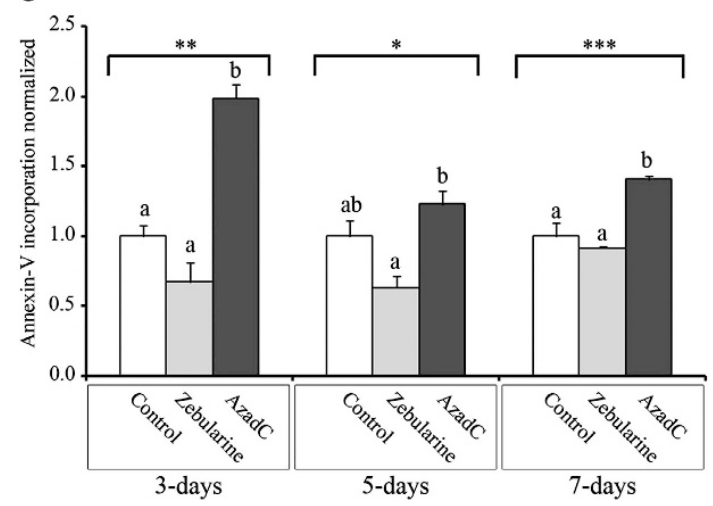

b

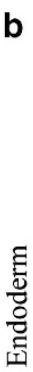

ह

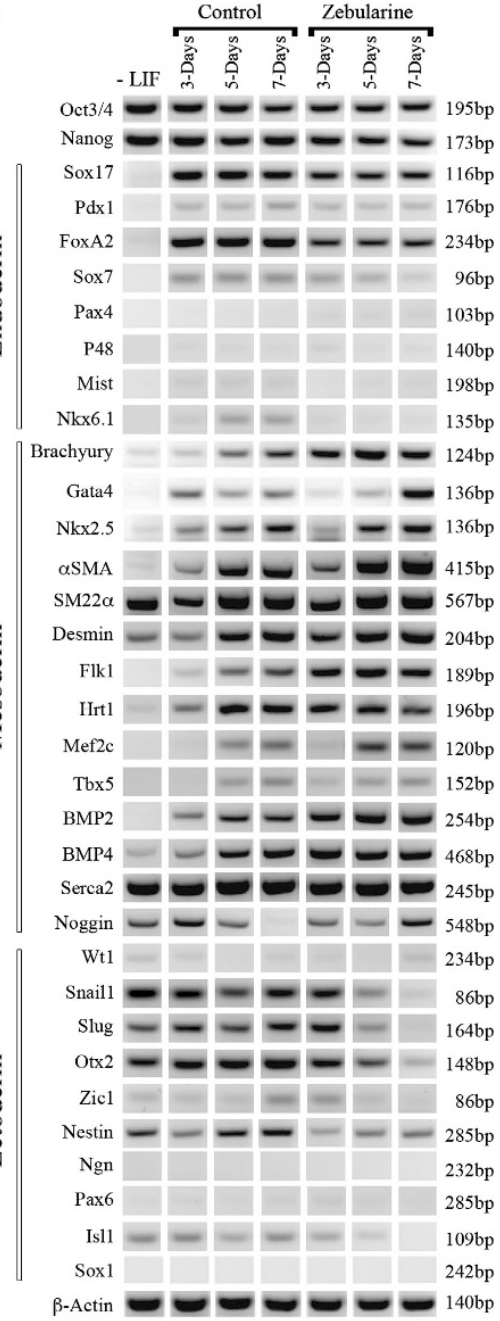

Figure 1 Effect of zebularine on mESC differentiation. (a) Detection and comparison of cardiac markers by RT-PCR in Control, AzadC, NO and zebularine treatment, undifferentiation markers are less detected and cardiac markers showed an enhanced expression after treatments. (b) Time course of zebularine treatment on lineage formation: $m E S C s$ cells were cultured as hanging drop during 3 days to form EBs and differentiate to derivatives of the three germ layers and then leaved in culture without treatment (Control) or treated with $30 \mu \mathrm{M}$ zebularine. Gene expression was assessed in parallel at differentiating days 3,5 and 7 . Cells cultured without LIF ( - LIF) are used as negative control for lineage formation. RT-PCR was performed with primers to detect pluripotency markers (Oct3/4 and Nanog), endoderm-specific markers (Sox17, Pdx1, FoxA2, Pax4, P48, Mist and Nkx6.1), mesoderm-specific markers (Brachyury, Gata4, Nkx2.5, $\alpha$ SMA, SM22 $\alpha$, Desmin, Flk1, Hrt1, Mef2c, tbx5, BMP2, BMP4, Serca2 and Noggin) and ectoderm-specific markers (Wt1, Snail1, Slug, Otx2, Zic1, Nestin, Ngn, Pax6. Islet1 and Sox1). $\beta$-Actin was used as the input control. (c) Apoptosis comparison for control-, zebularine- and AzadC-treated EBs. Time-course analysis and comparison of Annexin-V binding at differentiating days 3,5 and 7, indicating that cells treated with zebularine are not undergoing apoptosis. Values were normalized from the means of the controls. Data are representative of three independent experiments statistically analyzed with analysis of variance (ANOVA) I $\left({ }^{*} P<0.05,{ }^{* *} P<0.01\right.$ and $\left.{ }^{* * *} P<0.001\right)$. Different letters at the top of the bars represent statistically different values; same letters represent statistically same values in discriminatory analysis Tukey's $B$ test

Zebularine promotes the expression of cardiac-specific genes and proteins. We used real-time PCR to analyze the mRNA levels of genes related to cardiac differentiation, and genes involved in the functional machinery of cardiac cells in EBs leaved to spontaneous differentiation during 7 days (from now on defined as Control) and EBs treated with zebularine (from now on defined as Zebularine) (Figure 2a). We detected elevated mRNA levels of cardiac-precursor genes Nkx2.5 (enhanced 1.8-fold $(P>0.05)$ ) and Gata4 (enhanced 2.6-fold $(P>0.05)$ ), both essential for cardiac cell commitment, elevated the expression of genes whose encoded proteins are essential components of contractile cardiac machinery, such as Actc, cTnl, cTnT, Myh7, Myl7 and $M y / 2$, and increased the expression of other genes essential for cardiac development and function, such as Anf, Flk1, Hrt1 and Mef2c (Figure 2b).

Using western blotting (Figure 2c), we found that zebularine promotes the expression of proteins that are restricted to mesoderm and cardiac phenotypes, such as Gata4, Actc, Myh7, cTnt, Anf, Desmin, Flk1 and $\alpha$-actin. Immunostaining analysis (Figure 2d) showed that the precursor Gata4 was expressed at higher levels in zebularine-treated EBs and had 

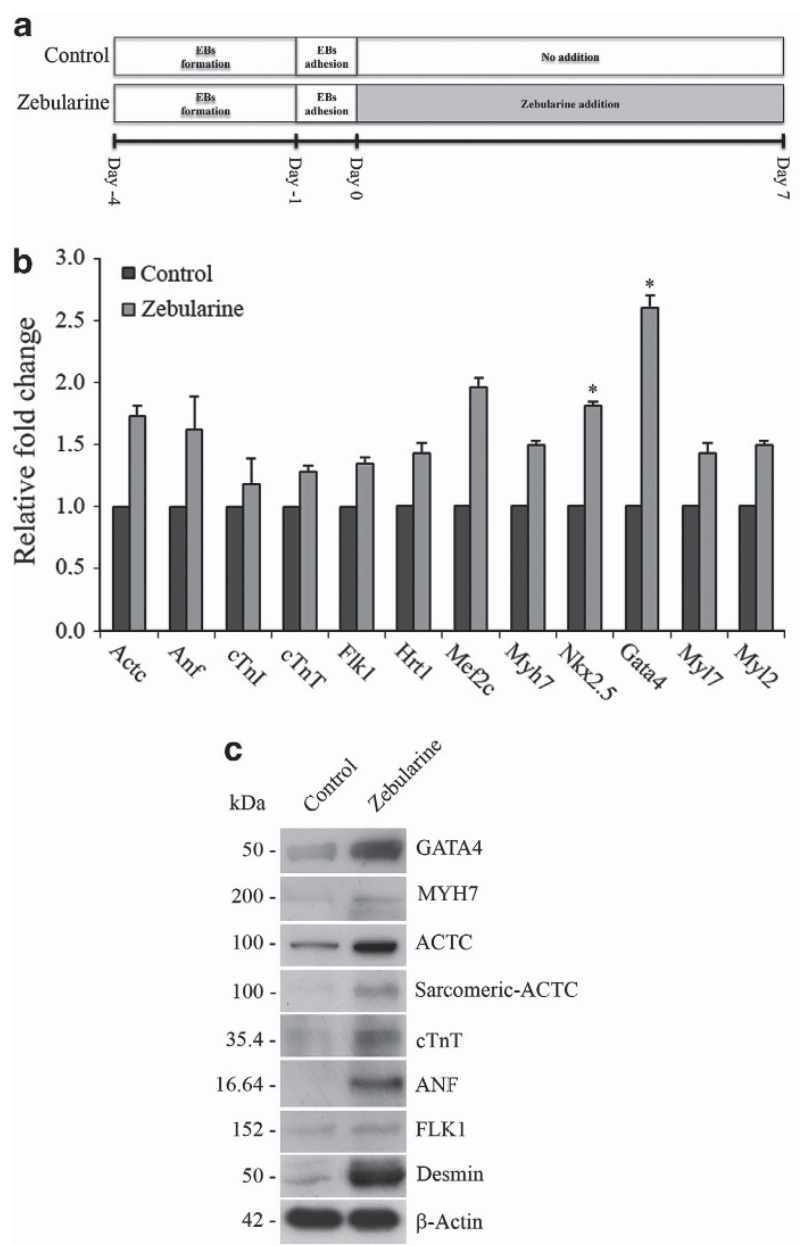

d
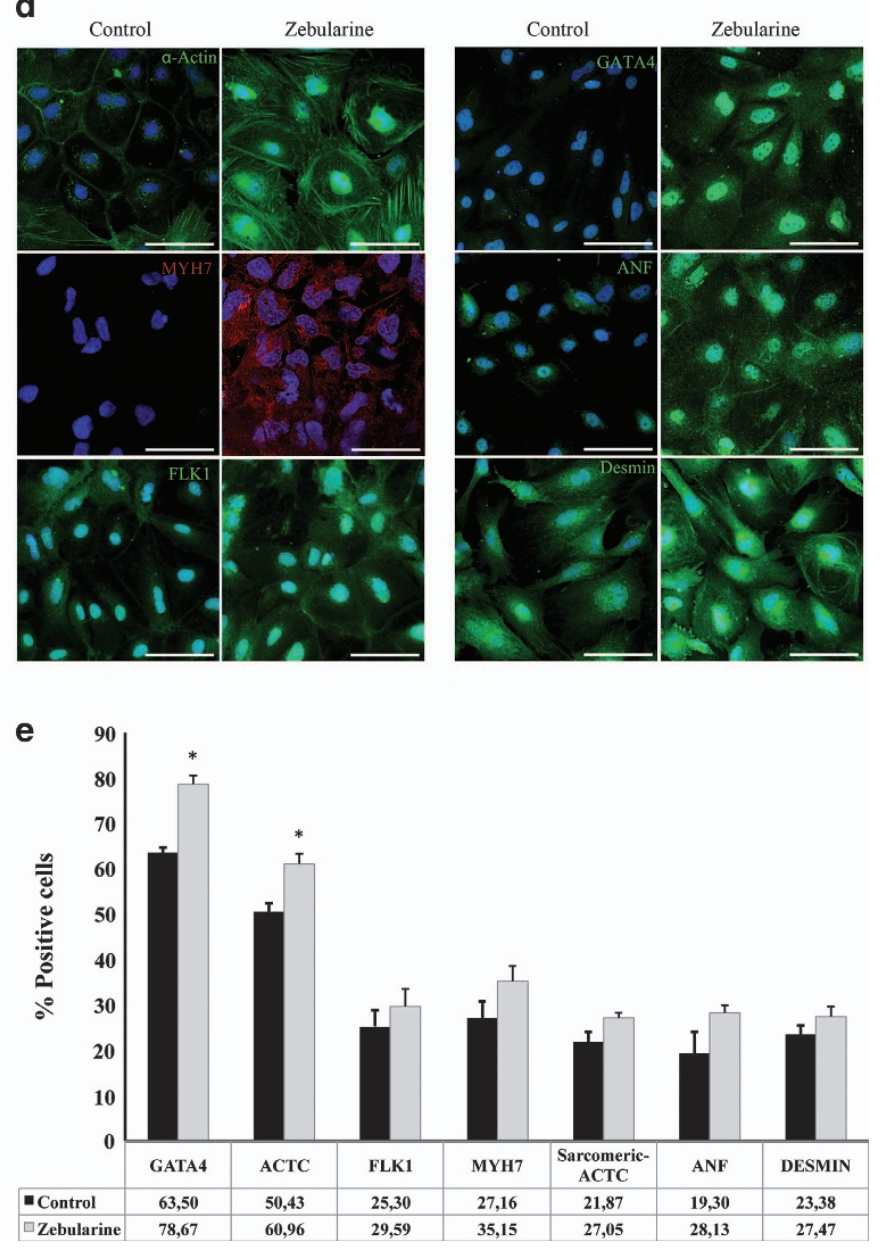

Figure 2 Zebularine promotes an overexpression of cardiac markers. (a) Timeline approach for differentiation of mESCs, showing the time periods for EBs formation, EBs adhesion, untreated control cells (no addition) and zebularine application. (b) Real-time PCR showing an overexpression of genes essential for cardiac development and function after zebularine treatment. The histograms represented the fold increase of each gene after treatment compared with the basal level of untreated control cells. Results are means \pm S.D. for three different experiments. (c) Western blot detection of cardiac protein expression; $\beta$-actin was used as a loading control. (d) Immunodetection corroborated the cardiac lineage markers after zebularine treatment; nuclei were stained with 4',6-diamidino-2-phenylindole (DAPI) (blue). Scale bars; $50 \mu \mathrm{m}$. (e) Results from flow cytometric analysis showing the percentage of cells expressing cardiac-specific proteins in control and zebularine conditions. Data are represented as mean \pm standard error $\left( \pm S\right.$.E.) for three different experiments. Statistical significance $\left({ }^{*} P<0.05\right)$ was determined by $t$-test

a primarily nuclear distribution, whereas no expression was detected in control cells. Moreover, Actc and Myh7 proteins were markedly increased in cells treated with zebularine. Actc was clearly distributed in the cellular cytoskeleton and cellular prolongations in comparison to control cells, which only expressed low levels of this protein. Myh7 demonstrated a similar cytoskeletal distribution in treated cells and was not detected in control. Anf was expressed after zebularine treatment but not in control cells. Furthermore, Flk1 and Desmin, two proteins involved in cardiovascular system development, had increased expression following zebularine treatment (Figure 2d). Finally, by flow cytometry analysis we detected that cells treated with zebularine were more positive to proteins involved in cardiac differentiation and functionality (Figure 2e). Zebularine-treated cells are 15.17\% more positive to Gata4, $10.53 \%$ to Actc, $4.29 \%$ to Flk1, $7.99 \%$ to Myh7, $5.18 \%$ to sarcomeric-Actc, $8.83 \%$ to Anf and $4.09 \%$ to
Desmin. These results suggest that zebularine is able to induce the expression of cardiac-specific genes and proteins.

The beating areas resulting from zebularine treatment respond to chronotropic drugs. Zebularine treatment resulted in the appearance of beating areas that showed rhythmic and coordinated contractions (Supplementary Movie 1). To determine whether these contractions were functional, we used cardiotropic drugs to alter beating frequency. We administrated isoproterenol, which acts on $\beta$-adrenergic receptors, and diltiazem, a calcium channel blocker that produces a decrease in cardiac rhythm, provoking negative ionotropic and chronotropic function. After the addition of $2 \mu \mathrm{M}$ isoproterenol (Figure 3a), we observed a $135.00 \%$ enhancement in contraction frequency after $1 \mathrm{~min}$ and a $126.25 \%$ enhancement after 2 min of exposure, demonstrating that isoproterenol provokes a very 


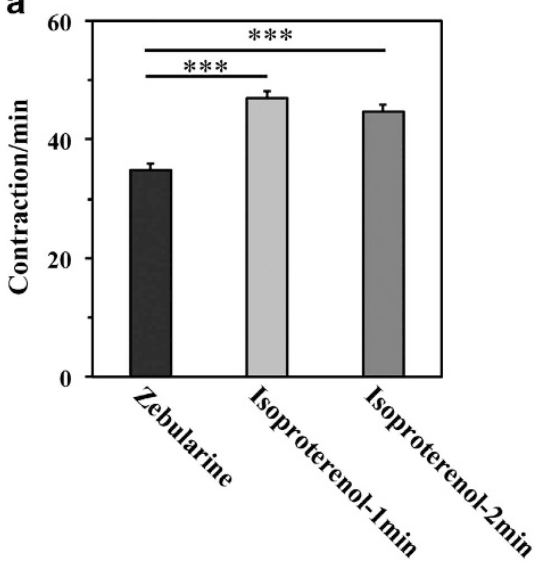

b

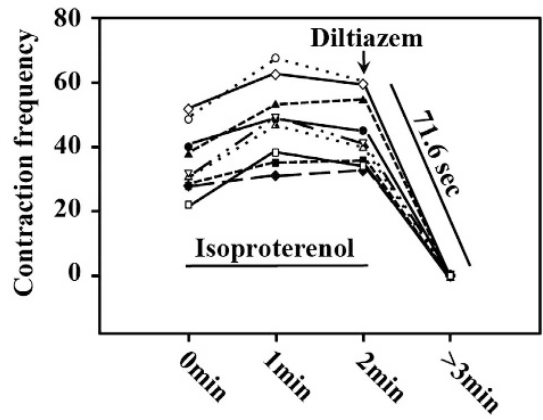

Figure 3 Effects of chronotropic drugs in zebularine-treated cells. (a) Median of beating frequency in samples 1 and 2 min after treatment with $2 \mu \mathrm{M}$ isoproterenol. Results are means \pm S.D. for 50 different areas from three experiments. ${ }^{* * *} \mathrm{~A}$ statistically significant difference of isoproterenol administration compared with zebularine (paired Student's $t$-test; $P<0.001$ ). (b) Contraction frequency registration of nine contractile areas from three different experiments showing that $2 \mu \mathrm{M}$ isoproterenol increased beating frequency and $50 \mu \mathrm{M}$ diltiazem was able to stop contractions $71.6 \mathrm{~s}$ after administration

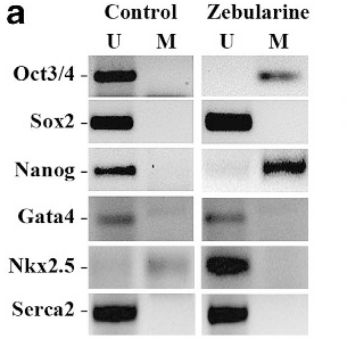

b

CpG sites 122344567899101112131415

Control 000000000000000

Zebularine 000000000000000

azadC 00000000000000

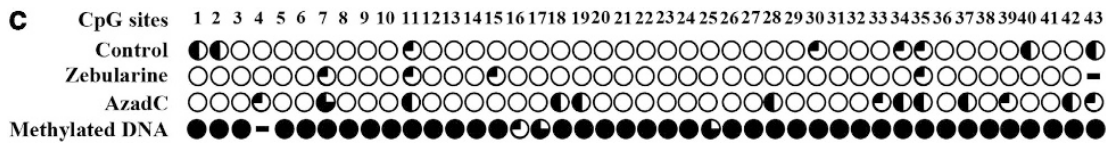

Figure 4 Analysis of gene promoter's methylation under zebularine treatment. (a) MSP of pluripotency and cardiac lineage markers showing that the promoters of both Oct3/4 and Nanog shifted from unmethylated $(\mathrm{U})$ to methylated $(\mathrm{M})$ state; the promoter of Nkx2.5 becomes unmethylated after zebularine treatment and no promoter methylation was detected in any of the other cardiac markers analyzed. (b) Bisulfite sequencing from five clones of Gata4 CpG island for Control, zebularine and AzadCtreated EBs, indicating that the promoter remains unmethylated in $15 \mathrm{CpG}$ sites. (c) Bisulfite sequencing from five clones of Nkx2.5 promoter revealed that zebularine unmethylated almost all of the $43 \mathrm{CpG}$ sites analyzed. The percentage of methylation is presented as the percentage of filled circles over total circles for a given $\mathrm{CpG}$ site from each clone analyzed: $\bigcirc=0 \% ; \bigcirc=40 \% ; \quad=60 \% ;-80 \% ; \quad=100 \%$

fast response in treated cells and that these cells possibly possess functional $\beta$-adrenergic receptors. On the other hand, and as we expected, $50 \mu \mathrm{M}$ diltiazem (Figure $3 \mathrm{~b}$ ) led to complete inhibition of contraction $71.6 \mathrm{~s}$ after its addition (Supplementary Movies 1-3). Hence, zebularine promotes the differentiation of mESCs towards contractile cells that respond to cardiotropic regulators.

Zebularine modifies the promoter methylation state of Nkx2.5. To determine whether zebularine produces changes in the methylation patterns, we studied gene promoter methylation status using methylation-specific PCR (MSP). As Figure $4 a$ depicts, the pluripotency markers Oct3/4 and Nanog were transcriptionally active in control samples (unmethylated). This contrasts with zebularine-treated EBs, which had methylated promoters, suggesting that zebularine induced methylation-based gene silencing. In contrast, the
Sox2 promoter was unmethylated in both samples, indicating that Sox2 expression was unaffected by zebularine. Moreover, the promoters of Gata4 and Serca2 were in an unmethylated state in both control and treated cells, suggesting that the expression of these genes was unaffected by zebularine.

Interestingly, Nkx2.5 was epigenetically repressed in control cells, but appeared unmethylated in zebularinetreated cells. As Nkx2.5 associates with members of the GATA family, activates cardiac structural genes and is essential to initiate the cardiac differentiation, these data indicate that zebularine was able to induce demethylation of Nkx2.5, which leads to its expression, thereby promoting the expression of other fundamental genes during the cardiac differentiation of ESCs.

To confirm and validate the promoter methylation status of Nkx2.5 and Gata4, bisulfite-treated genomic DNAs obtained from Control, zebularine and AzadC samples were amplified, 
cloned and sequenced. As shown in Figure 4b, we found that the methylation pattern did not change and the Gata4 promoter remains completely unmethylated, however; and in concordance with the MSP results, Nkx2.5 promoter was almost completely unmethylated for zebularine and predominately methylated for AzadC (Figure 4c).

Consequently, we analyzed the activity of DNA demethylases and DNMTs. Following zebularine addition, DNA demethylase activity was significantly enhanced by $129.01 \%$ $(P<0.01)$, whereas DNMT activity was reduced $14.20 \%$ $(P=0.01)$ compared with control cells (Figure 5a). These data suggest that promoter methylation is reduced when cells are treated with zebularine and subsequently zebularine acts on DNMTs, decreasing their activity.

We also studied histone methyltransferase (HMT) activity for histone $\mathrm{H} 3$ lysine 9 (H3K9) and histone H3 lysine 4 (H3K4). After zebularine treatment, we found a $60.77 \%(P=0.017)$ reduction of HMT activity at $\mathrm{H} 3 \mathrm{~K} 9$, which is considered a marker for heterochromatin. In addition, the HMT activity at $\mathrm{H} 3 \mathrm{~K} 4$, a hallmark of euchromatin, was increased by $32.8 \%$ $(P=0.01)$ after zebularine treatment (Figure $5 \mathrm{~b})$. We also detected that histone deacetylase (HDAC) activity was reduced by $52.74 \%(P=0.017)$ compared with control samples, indicating that chromatin exists in a more relaxed
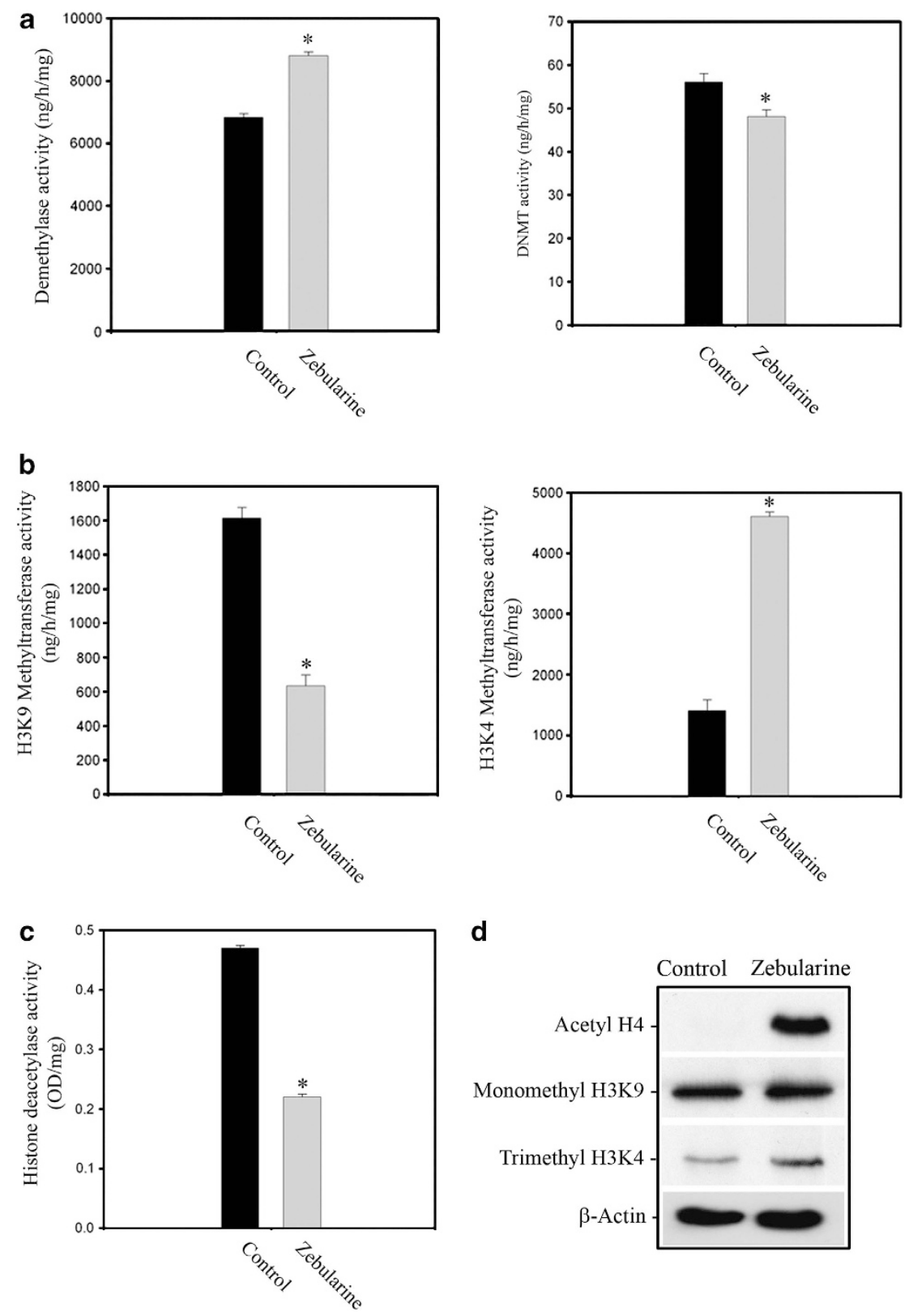

d

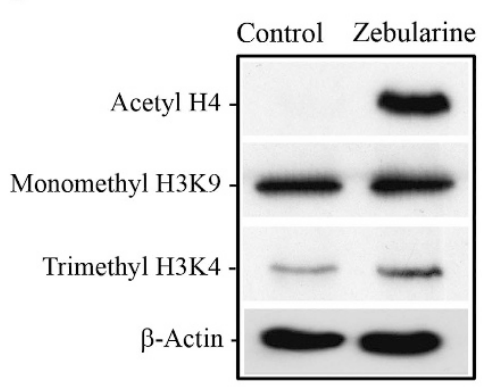

Figure 5 Zebularine treatment caused (a) an increment of global demethylase activity and a decrease of DNTMs activity (b) a decrease of HMT (H3K9) and increase of H3K4 (c) reduction of global HDAC activity. Blots are representative of 4 independent experiments. (d) Western blot detection after zebularine treatment of acetylated state of histone $\mathrm{H} 4$, and methylated state of histones $\mathrm{H} 3 \mathrm{~K} 4 \mathrm{me} 3$ and $\mathrm{H} 3 \mathrm{~K} 9 \mathrm{me} 1, \beta$-actin was used as loading control 
conformation in treated samples (Figure 5c). Although zebularine enhanced histone $\mathrm{H} 4$ acetylation, the acetylation state of histones plays a central role in determining gene expression and its overexpression could indicate a transcriptional upregulation; H3K4 and H3K9 methylation are detectable in zebularine-treated cells, the level of $\mathrm{H} 3 \mathrm{~K} 9$ methylation appears no different compared with control and H3K4 methylation appears slightly increased (Figure $5 d$ ), indicating the establishment of a specific pattern of histone modification.

These data indicate that zebularine acts as a chromatinmodifying agent, inducing methylation and silencing of Oct3/4 and Nanog, both of which are essential to maintain pluripotency. In addition, this drug is able to demethylate and increase the expression of Nkx2.5, which directs cells to enter a cardiomyocyte differentiation program. Moreover, zebularine indirectly alters the activity of enzymes that are implicated in the epigenetic regulation of gene transcription and chromatin structure.

Zebularine alters global gene expression profiling. To characterize the genome-wide gene expression profile, we used Affymetrix microarray platform. A set of differentially expressed genes is presented as a heatmap to illustrate groups of coregulated genes; hierarchical clustering (Figure 6a) indicated that the gene expression profile of zebularine is distinct from that of control. The data were then globally normalized, filtered and deposited in NCBI's GEO database (GSE29072). Using Gene Ontology categories, 266 genes (119 upregulated and 147 downregulated) were identified from a total of 45102 genes as having an expression level that differed significantly $(P<0.001)$ upon zebularine treatment. The potential functions and known biological roles of these genes are listed in Supplementary Table 2. Data were most associated with biological process, system development, organ and multiorgan development, anatomical structure development, anatomical structure morphogenesis, cellular components and molecular functions. Some of the genes upregulated by zebularine matched the mesoderm markers, these include BMP4 and Brachyury.

We compared our microarray results with the results from other studies by analyzing all mouse GEO studies that used the mouse Affymetrix platform in the GEO database. A high positive score implies that the mouse GEO studies shares over- and underexpressed signatures with our experiment, whereas a high negative score indicates a reverse or antipattern compared with our study. The scores were
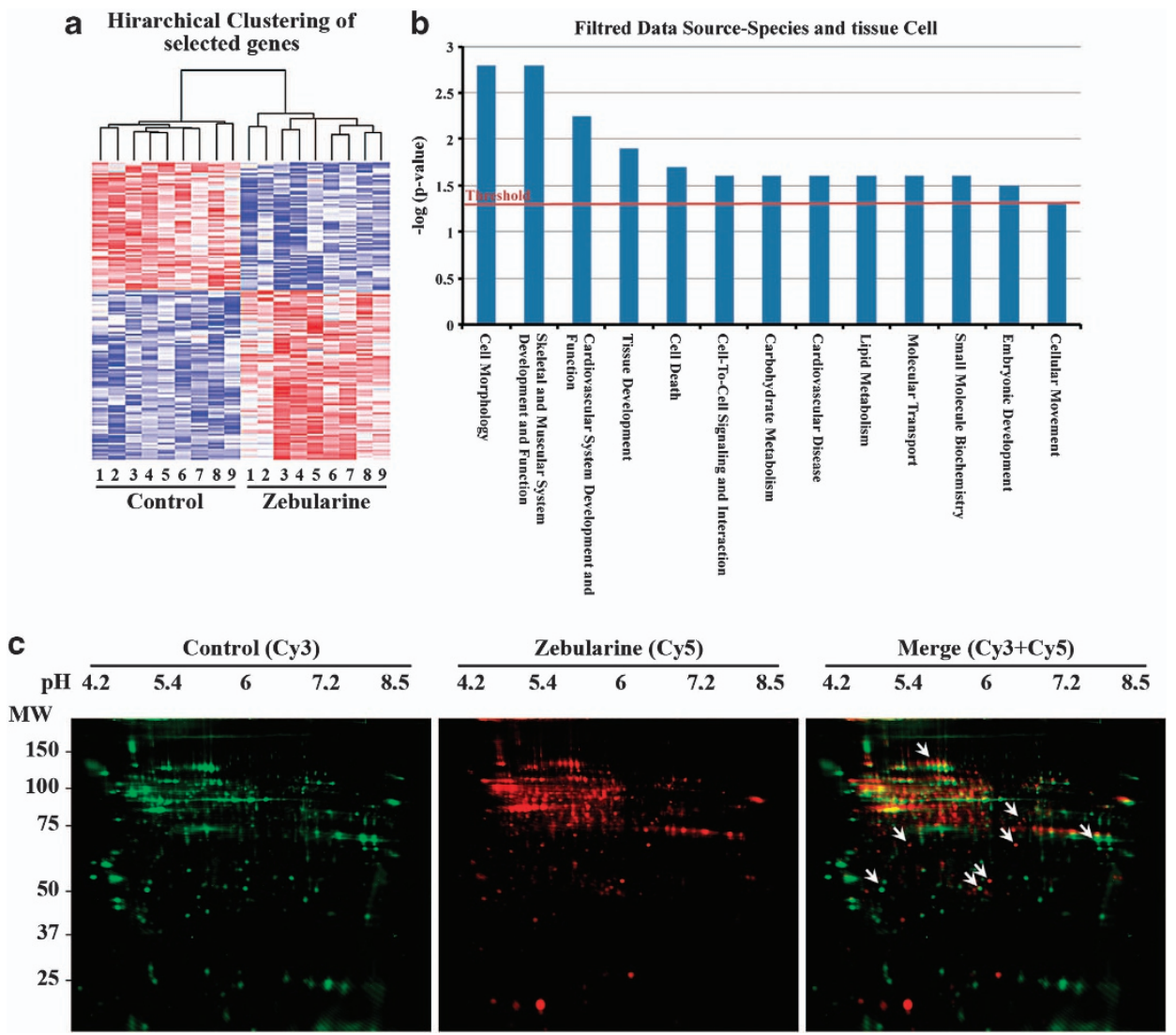

Figure 6 Microarrays, IPA analysis and proteomics assays for zebularine-treated cells. (a) Hierarchical clustering of the gene expression changes between zebularine and Control. The columns represent different replica of each condition replica. A red color represents upregulation, whereas a blue color represents downregulation. (b) Plot for biological functions generated by IPA analysis showing enhanced threshold for those related to cardiomuscular development. Enrichment score (y axis) is reported as the minus log transformation on the geometric mean of $P$-values from the enriched annotation terms associating with one or more of the gene group members. The genes are clustered into significantly enriched groups for specific biological functions. (c) Comparison of control- and zebularine-treated cells proteins using 2D-DIGE. Protein fractions from control were labeled with Cy3 (green) and zebularine ones with Cy5 (red), and then mixed. The mixed protein samples were separated by isoelectric focusing, and then SDS-PAGE. Merge picture from the superposition of fluorescence images shows a pool of proteins with differential mobility in zebularine condition (arrows) 
(A)

\begin{tabular}{|c|c|c|}
\hline GEO study & $\begin{array}{l}\text { Similarity } \\
\text { score }\end{array}$ & $P$-value \\
\hline $\begin{array}{l}\text { DNA demethylation effect on dermal fibroblasts: Aza-dC }<=>\text { untreated (agent) (GSE4696) } \\
\text { Transcription factors Nanog and Oct4 knockdown effect on ESCs: Nanog knockdown }<=>\text { Control } \\
\text { (protocol) (GSE4189) }\end{array}$ & $\begin{array}{l}1.04 \\
1\end{array}$ & $\begin{array}{l}<0.0001 \\
<0.0001\end{array}$ \\
\hline ESC line response to the conditional expression of neurogenin $3: \mathbf{3}$ days $<=>\mathbf{0}$ days (time) (GSE3653) & 0.95 & $<0.0001$ \\
\hline NA demethylation effect on terminally differentiated cells: 5 -aza-2dC $<=>$ control (agent) (GSE4768) & 0.885 & $<0.0001$ \\
\hline Cell culture model of extraembryonic endoderm: R1 $<=>$ IM8A1-I (ratio) (cell line) & 0.883 & $<0.0001$ \\
\hline Hair follicle and skin molecular signatures: matrix $<=>$ dermal papilla (cell type) & 0.846 & $<0.0001$ \\
\hline Transcription factor Nrl deficiency effect on photoreceptor development: $\mathrm{P} 2<=>\mathrm{E} 16$ (development stage) & 0.839 & $<0.0001$ \\
\hline Glucosamine and high glucose effect on renal mesangial cells: $25 \mathrm{mM}$ glucose $<=>$ control (agent) & 0.837 & $<0.0001$ \\
\hline Phosgene effect on lungs: time course $12 \mathrm{~h}<=>0 \mathrm{~h}$ (time) & 0.835 & $<0.0001$ \\
\hline Blastocyst response to various MAPK pathway inhibitors (MOE430A): JNK inhibitor $<=>$ untreated (ratio) (agent) & 0.827 & $<0.0001$ \\
\hline DNA demethylation effect on terminally differentiated cells: osteoblast $<=>$ fibroblast (cell type) & 0.822 & $<0.0001$ \\
\hline Blastocyst response to various MAPK pathway inhibitors (MOE430 2.0): JNK inhibitor $<=>$ untreated (agent) & 0.818 & $<0.0001$ \\
\hline $\begin{array}{l}\text { Trans-10, cis-12-conjugated linoleic acid delipidiative effect on white adipose tissues: time course trans-10, cis- } \\
\text { 12-conjugated linoleic acid }<=>\text { control (agent) }\end{array}$ & 0.807 & $<0.0001$ \\
\hline Estrogen effect on lung: time course $6 \mathrm{~h}<=>3 \mathrm{~h}$ (time) & 0.801 & $<0.0001$ \\
\hline $\begin{array}{l}\text { Mechanical stress effect on fibroblasts from various fetal tissues (MG-430A): tendon fibroblast }<=>\text { skin } \\
\text { fibroblast (cell line) }\end{array}$ & 0.797 & $<0.0001$ \\
\hline Spinal cord injury model: time course site of trauma $<=>$ caudal to trauma (specimen) & 0.794 & $<0.0001$ \\
\hline DNA demethylation effect on terminally differentiated cells: osteoblast $<=>$ chondrocyte (cell type) & 0.791 & $<0.0001$ \\
\hline $\begin{array}{l}\text { Transcription factor Oct1-deficient fibroblast response to ionizing radiation }(430 \mathrm{~A}): \gamma \text {-radiation }<=>\text { control } \\
\text { (agent) }\end{array}$ & 0.79 & $<0.0001$ \\
\hline Pancreatic development (MG-U74B): E14.5<=> E12.5 (age) & 0.79 & $<0.0001$ \\
\hline $\begin{array}{l}\text { Topoisomerase } \| \beta \text { deficiency effect on the developing embryonic brain: top } \| \beta \text { null }<=>\text { wild type (genotype/ } \\
\text { variation) }\end{array}$ & 0.79 & $<0.0001$ \\
\hline Phosgene effect on lungs: time course $24 \mathrm{~h}<=>0 \mathrm{~h}$ (time) & 0.788 & $<0.0001$ \\
\hline Oocyte development (MOE430B): secondary follicle $<=>$ primary follicle (development stage) & 0.785 & $<0.0001$ \\
\hline Oocyte development (MOE430B): 12 days $<=>6$ days (age) & 0.785 & $<0.0001$ \\
\hline $\begin{array}{l}\mathrm{CH} 1 \text { domain deletion, p300 and CBP heterozygous-null mutant fibroblasts response to hypoxia: } \\
\text { normoxia }<=>\text { hypoxia (stress) }\end{array}$ & 0.78 & $<0.0001$ \\
\hline Hair follicle and skin molecular signatures: matrix $<=>$ dermal fibroblasts (cell type) & 0.772 & 0.006818 \\
\hline Conjugated linoleic acid delipidative effect on obese line: time course (dye-swap) 14 days (ratio) (time) & 0.771 & 0.006818 \\
\hline Cardiac development in embryo: E14.5 < = > E11.5 (development stage) (GSE1479) & 0.771 & 0.006818 \\
\hline Pancreatic development (MG-U74B): E15.5<=>E12.5 (age) & 0.763 & 0.006818 \\
\hline Differential repression of TLR responses by PPARg and LXRs: GW7845 $<=>$ none (treatment) & 0.76 & 0.006818 \\
\hline Corneal stromal cell differentiation: adult $<=>10$ days postnatal (protocol) & 0.758 & 0.006818 \\
\hline Fibroblast growth factor 2 effect on embryonic fibroblast: dose response $40 \mathrm{ng} / \mathrm{ml}<=>4 \mathrm{ng} / \mathrm{ml}$ (ratio) (dose) & 0.75 & 0.01271 \\
\hline Epididymis development: postnatal day $0.5<=>$ gestational day 18 (age) & 0.75 & 0.01815 \\
\hline Pancreatic development (MG-U74B): E13.5<=>E12.5 (age) & 0.748 & 0.01815 \\
\hline ERK MAP kinase inactivation during G0/G1-to-S-phase transition: time course $\mathrm{FGF}<=>$ control (protocol) & 0.748 & 0.01852 \\
\hline Testis developmental time course: embryonic (MG-U74A): 18.5 d.p.c. $<=>11.5$ d.pc. (development stage) & 0.746 & 0.01852 \\
\hline Phosgene effect on lungs: time course $8 \mathrm{~h}<=>0 \mathrm{~h}$ (time) & 0.741 & 0.01852 \\
\hline Testis development: gestation day $16<=>$ gestation day 12 (time) & 0.741 & 0.01852 \\
\hline Cardiac development in embryo: E16.5 < = > E11.5 (development stage) (GSE1479) & 0.74 & 0.01852 \\
\hline Ovary development: gestational day $14<=>$ gestational day 12 (age) & 0.738 & 0.01852 \\
\hline Phosgene effect on lungs: time course $48 \mathrm{~h}<=>0 \mathrm{~h}$ (time) & 0.736 & 0.01852 \\
\hline Acute myocardial infarction model: time course (MG-U74B) $48 \mathrm{~h}<=>4 \mathrm{~h}$ (time) & 0.736 & 0.01852 \\
\hline Heart failure and NO eNOS knockout $<=>$ wild type (strain) & 0.736 & 0.01852 \\
\hline $\begin{array}{l}\text { Embryonic kidney: ureteric bud and metanephric mesenchyme (MOE430 2.0): ureteric bud tip }<=>\text { ureteric bud } \\
\text { stalk (tissue) }\end{array}$ & 0.734 & 0.01852 \\
\hline MAP kinase activation effect on heart: time course MKK3bE transgenic $<=>$ control (genotype/variation) & 0.729 & 0.01852 \\
\hline Glycerol kinase knockout effect on liver glycerol kinase knockout $<=>$ wild type (genotype/variation) & 0.729 & 0.01852 \\
\hline $\begin{array}{l}\text { Myotube response to PGC- } 1 \alpha \text {-induced mitochondrial biogenesis: time course (MG-U74B) } 3 \text { days }<=>0 \text { days } \\
\text { (time) }\end{array}$ & 0.728 & 0.02131 \\
\hline Cardiac development in embryo: E18.5 < = > E11.5 (development stage) (GSE1479) & 0.725 & 0.02131 \\
\hline Pancreatic development (MG-U74B): E16.5 $<=>$ E12.5 (age) & 0.725 & 0.02131 \\
\hline $\begin{array}{l}\text { Lymphotoxin- } \beta \text { receptor signaling inhibition effect on lymph nodes: time course (MG-430B) } 35 \text { days }<=>27 \text { days } \\
\text { (time) }\end{array}$ & 0.72 & 0.02394 \\
\hline $\begin{array}{l}\text { Spermatogonial stem cell activity in testis laminin binding germ cells (MG-U74C): laminin binding }<=>\text { interstitial } \\
\text { (cell type) }\end{array}$ & 0.72 & 0.02394 \\
\hline Phosgene effect on lungs: time course $72 \mathrm{~h}<=>0 \mathrm{~h}$ (time) & 0.72 & 0.02394 \\
\hline Pyruvate effect on muscle cells: sodium pyruvate $<=>$ untreated (agent) & 0.72 & 0.02394 \\
\hline Hematopoietic cells at various stages of differentiation: granulocyte $<=>$ ST-HSC (ratio) (development stage) & 0.719 & 0.02394 \\
\hline Hippocampus of various inbred strains: DBA/2J $<=>129 \mathrm{~S} 1 / \mathrm{Sv} / \mathrm{Im}$ (strain) & 0.717 & 0.02706 \\
\hline Phosgene effect on lungs: time course $8 \mathrm{~h}<=>4 \mathrm{~h}$ (time) & 0.716 & 0.02706 \\
\hline $\begin{array}{l}\text { Gonadal somatic cells during the critical period of sex determination: time course } 11.5 \text { d.p.c. }<=>10.5 \text { d.p.c. } \\
\text { (age) }\end{array}$ & 0.714 & 0.0303 \\
\hline Embryonal carcinoma cell line response to retinoic acid or trichostatin $\mathrm{A}: \mathrm{t}$ & 0.711 & 0.03571 \\
\hline Uniparental duplication of chromosome 7 regions effect on various tissues (MG-U74A): 13.5 d.p.c. & 0.709 & 0.03892 \\
\hline
\end{tabular}


(A)

\begin{tabular}{|c|c|c|}
\hline GEO study & $\begin{array}{l}\text { Similarity } \\
\text { score }\end{array}$ & $P$-value \\
\hline MAP kinase activation effect on heart: time course male $<=>$ female (gender) & 0.708 & 0.04206 \\
\hline Acute myocardial infarction model: time course (MG-U74A) $24 \mathrm{~h}<=>12 \mathrm{~h}$ (time) & 0.706 & 0.04239 \\
\hline $\begin{array}{l}\text { Transcription factor Oct1 deficient fibroblast response to ionizing radiation }(430 \mathrm{~B}): \gamma \text {-radiation }<=>\text { control } \\
\text { (agent) }\end{array}$ & 0.705 & 0.04239 \\
\hline Phosgene effect on lungs: time course phosgene $<=>$ none (agent) & 0.705 & 0.04239 \\
\hline Osteoblast differentiation (MG-U74B): 17 days $<=>7$ days (time) & 0.704 & 0.04239 \\
\hline Ovary development: gestational day $14<=>$ gestational day 11 (age) & 0.702 & 0.04239 \\
\hline Hyperoxic lung injury (U74Cv2): Nrf2 mutant $<=>$ wild type (strain) & 0.701 & 0.04487 \\
\hline Testis development: gestation day $14<=>$ gestation day 12 (time) & 0.7 & 0.04487 \\
\hline $\begin{array}{l}\text { Embryonic kidney: ureteric bud and metanephric mesenchyme (MOE430 2.0): ureteric bud tip }<=>\text { metanephric } \\
\text { mesenchyme (tissue) }\end{array}$ & 0.699 & 0.04611 \\
\hline Oocyte development (MOE430B): 22 days $<=>6$ days (age) & 0.696 & 0.04611 \\
\hline $\begin{array}{l}\text { Cystic fibrosis transmembrane conductance regulator deficiency in different genetic backgrounds: CFTR } \\
\text { deficient }<=>\text { control (genotype/variation) }\end{array}$ & 0.695 & 0.04611 \\
\hline Androgen effect on spermatogenesis: time course 10 days $<=>8$ days (age) & 0.695 & 0.04878 \\
\hline
\end{tabular}

(B)

\section{GEO study}

\section{Similarity P-value \\ score}

Guided differentiation into dopaminergic neurons and random differentiation into EBs neural precursors (stage 3 )

(development stage)

Myogenic transcription factor MyoD mutant expression effect on embryonic fibroblast: time course $24 \mathrm{~h}<=>6 \mathrm{~h}$ (time)

Spermatogonial stem cell self-renewal: time course $18 \mathrm{~h}<=>$ control (time)

Spermatogonial stem cell self-renewal: time course GDNF, GFR $\alpha 1$ withdrawal $<=>$ GDNF, GFR $\alpha 1$ pre-

withdrawal (protocol)

Male and female salivary gland comparison: sublingual gland $<=>$ parotid gland (tissue)

Embryonic stem cell line response to the conditional expression of neurogenin 3 undifferentiated:

ESCs $<=>$ EBs (development stage) (GSE3653)

Pubertal mammary gland development: 4 weeks $<=>3$ weeks (age)

Medullary thymic epithelial cells medullary TEC $<=>$ dendritic (cell type)

Chondrocyte differentiation: time course 9 days $<=>3$ days (time)

Hematopoietic stem cell proliferation after 5 -fluorouracil treatment: time course 30 days $<=>0$ days (time)

Spermatogonial stem cell self-renewal: time course $4 \mathrm{~h}<=>$ control (time)

Corneal stromal cell differentiation cell culture $<=>$ adult (protocol)

Brown fat cell response to PGC- $1 \alpha$ and PGC- $1 \beta$ deficiency: PGC- $1 \beta$ siRNA $<=>$ control siRNA (agent)

Embryonic stem cell differentiation induced by various chemicals: time course HMBA (agent)

Hair follicle and skin molecular signatures: melanocytes $<=>$ matrix (cell type)

Transcription factor Egr3 expression effect on primary myotubes (MG-430A): truncated Egr3 $<=>$ wild-type Egr3 (genotype/variation)

Testosterone effect on female lacrimal, meibomian and submandibular glands: submandibular gland $<=>$ meibomian gland (tissue)

Hair follicle and skin molecular signatures: outer root sheath $<=>$ matrix (cell.type)

Chondrocyte differentiation: time course 9 days $<=>6$ days (time)

Guided differentiation into dopaminergic neurons and random differentiation into EB-guided differentiation (growth protocol)

Testis development: postnatal day $2<=>$ gestation day 16 (time)

Cardiac development in embryo: whole heart $<=>$ both ventricles (tissue)

ESC differentiation induced by various chemicals: time course RA (agent) (Platform GPL1261)

Corneal stromal cell differentiation: myofibroblast $<=>$ cornea (cell type)

Embryonic stem cell line response to the conditional expression of neurogenin 3: 10 days $<=>0$ days (time) (GSE3653)

Peripheral myelin protein 22 gene dosage and point mutation effect on sciatic nerve: PMP22 knockout $<=>$ wild type (genotype/variation)

Corneal stromal cell differentiation: fibroblast $<=>$ cornea (cell type)
$-0.695$

$-0.698$

$-0.702$

$-0.706$

$-0.707$

$-0.711$

$-0.711$

$-0.712$

$-0.712$

$-0.713$

$-0.714$

$-0.716$

$-0.718$

$-0.721$

0.04611

0.04611

0.04239

0.04239

0.04239

0.03571

0.03571

0.03309

0.03309

0.03309

0.0303

0.02706

0.02394

0.02131

$-0.721$

0.02131

$-0.722$

0.02131

$-0.722$

0.02131

$-0.729$

0.01852

$-0.73$

0.01852

$-0.734$

0.01852

$-0.738$

0.01852

0.01852

$-0.741$

$-0.744$

$-0.747$

$-0.75$

0.01852

0.01852

0.01852

$-0.751$

$-0.754$

$-0.755$

0.01815

0.01271

0.01271

0.01271

0.006818

$-0.765$

0.006818

$-0.766$

$-0.767$

0.006818

0.006818

0.006818

$-0.77$

$-0.773$

0.006818

0.006818

0.006818

0.006818

$-0.778$

0.006818

0.006818

$-0.78$

$<0.0001$ 
Table 1 (continued)

(B)

\begin{tabular}{|c|c|c|}
\hline GEO study & $\begin{array}{l}\text { Similarity } \\
\text { score }\end{array}$ & $P$-value \\
\hline Endothelial progenitor cells in fetal liver: feeder cell layer $<=>$ LEPs_Sca1 minus (cell type) & -0.789 & $<0.0001$ \\
\hline ESC line response to the conditional expression of neurogenin 3: 10 days $<=>3$ days (time) & -0.791 & $<0.0001$ \\
\hline Hematopoietic stem cell proliferation after 5 -fluorouracil treatment: time course 6 days $<=>0$ days (time) & -0.794 & $<0.0001$ \\
\hline ESC differentiation induced by various chemicals: time course 6 days (time) & -0.798 & $<0.0001$ \\
\hline Cell culture model of extraembryonic endoderm: ICR $<=>129 / \mathrm{Sv}$ (ratio) (strain) & -0.807 & $<0.0001$ \\
\hline Cell culture model of extraembryonic endoderm: XEN1-3 $<=>$ R1 (ratio) (cell line) & -0.807 & $<0.0001$ \\
\hline Cell culture model of extraembryonic endoderm: $\mathrm{PO}<=>129 / \mathrm{Sv}$ (strain) & -0.81 & $<0.0001$ \\
\hline Antenatal steroid effect on the placenta: dexamethasone $<=>$ control (agent) & -0.823 & $<0.0001$ \\
\hline $\begin{array}{l}\text { Protein tyrosine kinase Src R388A mutant rescue by imidazole in living cells: time course Src R388A } \\
\text { Y527F }<=>\text { Src D386N Y527F (cell line) }\end{array}$ & -0.836 & $<0.0001$ \\
\hline Acute myocardial infarction model: time course (MG-U74B) $4 \mathrm{~h}<=>24 \mathrm{~h}$ (time) & -0.855 & $<0.0001$ \\
\hline ESC differentiation induced by various chemicals: time course 2 days (time) (Platform GPL1261) & -0.932 & $<0.0001$ \\
\hline $\begin{array}{l}\text { Embryonic stem cell differentiation induced by various chemicals: time course } 4 \text { days (time) (Platform } \\
\text { GPL1261) }\end{array}$ & -0.963 & $<0.0001$ \\
\hline ESC differentiation induced by various chemicals: time course DMSO (agent) (Platform GPL1261) & -1.1 & $<0.0001$ \\
\hline
\end{tabular}

Bold text denotes studies that involve the use of different agents (AzadC, Retinoic Acid, DMSO) for ESC differentiation, cardiac development and DNA demethylation, and the GEO accession number for these studies are in italics within parentheses.

calculated using weighted Kolmogorov-Smirnov statistics, which were then used to generate a Connectivity Map. ${ }^{24}$ These computations were carried out using the GEO query package of $\mathrm{R}$ Bioconductor and the statistical packages in $\mathrm{R}$. Out of the microarrays we analyzed, 3750 showed a significantly similar or significantly reverse signature to our experiment; as a first approximation, we focused on similarity/ dissimilarity scores with a $P<0.05$ and found 71 studies with high similarity to our results ( $P$-values from 0.695 to 1$)$ and 54 studies with low similarity $(P$-values from -0.695 to -1$)$ (Table 1).

As this classification is very approximate and gives only basic information, we also analyzed the data using IPA to classify specific groups of genes involved in cellular functions related to cardiogenesis (Figure $6 \mathrm{~b}$ ). Interestingly, the most often recorded biological functions were related to skeletal, muscular and cardiovascular system development and function, tissue development, cell-to-cell signaling and embryonic development. In addition to these gene expression changes, 2D-DIGE proteomics assay results showed that zebularine also affects protein mobility patterns, altering the acidic shift in several proteins (Figure 6c).

Zebularine enhances the expression of cardiac lineage markers in hESCs. We speculated whether zebularine was able to produce the same effect on hESCs. To address this issue, we used HS-181 - an hESC cell line. After 7 days of treatment, no beating areas were detected. To determine whether zebularine-treated hESCs possessed cardiac expression markers, we analyzed the gene expression using RT-PCR (Figure 7a). As with mESCs, we detected Gata4 expression in control and treated samples, and increased expression of Actc, Myh7, Myh6, cTnl, Serca2 and Anf in zebularine-differentiated cells; however, no expression of Myl2 and Myl7 was detected, possibly explaining the absence of contractile areas in treated cells. We then studied the protein expression using immunostaining (Figure $7 \mathrm{~b}$ ) and detected that zebularine slightly enhanced the protein levels of Gata4, Myh7, Actc and Anf. In addition, results from an hESC-specific protein array demonstrated a slight inhibition of pluripotency marker expression and increased levels of mesodermic proteins after zebularine treatment (Figures 7c and d). As a result, zebularine is able to induce cardiacspecific gene and protein expression in HS-181, although less effectively than in mESCs. Future comparative investigations will shed light on whether zebularine is able to induce complete cardiac differentiation in various cell types.

\section{Discussion}

It has been widely demonstrated that ESCs are able to give rise to cardiomyocytes when treated with growth factors and chemical compounds. ${ }^{25-28}$ Among the many different protocols used to differentiate ESCs towards cardiomyocytes, $\mathrm{NO}$ addition to ESC culture was able to upregulate cardiomyogenesis processes and inhibit cell death. ${ }^{29-31}$ AzadC has also been demonstrated to be an activator of the cardiac differentiation, ${ }^{15}$ although $1 \mu \mathrm{M}$ of AzadC leads to cell death and disappearance of the cardiac phenotype. Thus, AzadC possesses a significant limitation in producing cardiac-like cells from ESCs because of its cytotoxicity and inability to maintain a cardiac phenotype.

In this study, we demonstrated that zebularine is able to induce a mesodermal differentiation in mESCs and found that its application led to the increased expression of cardiacrestricted genes. Beyond the overexpression of cardiomyocyte-specific markers, we found that the pluripotency markers were downregulated. Interestingly, based on gene expression, zebularine appears to be more efficient at promoting the development of cardiac phenotypes than AzadC and NO, particularly in light of some reports suggesting that $A$ zadC fails to differentiate stem cells to a cardiac lineage. . $^{32,33}$

Furthermore, protein expression analysis confirmed that proteins involved in cardiac differentiation and functionality were highly expressed in the treated cells. These data were supported by immunostaining and flow cytometry analysis. To 


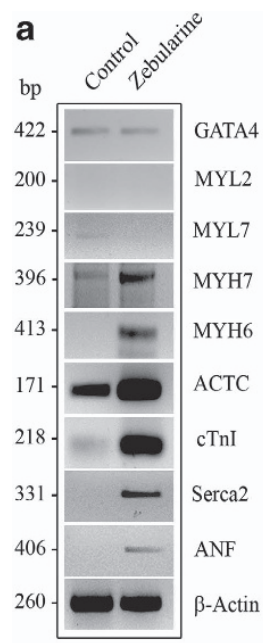

b

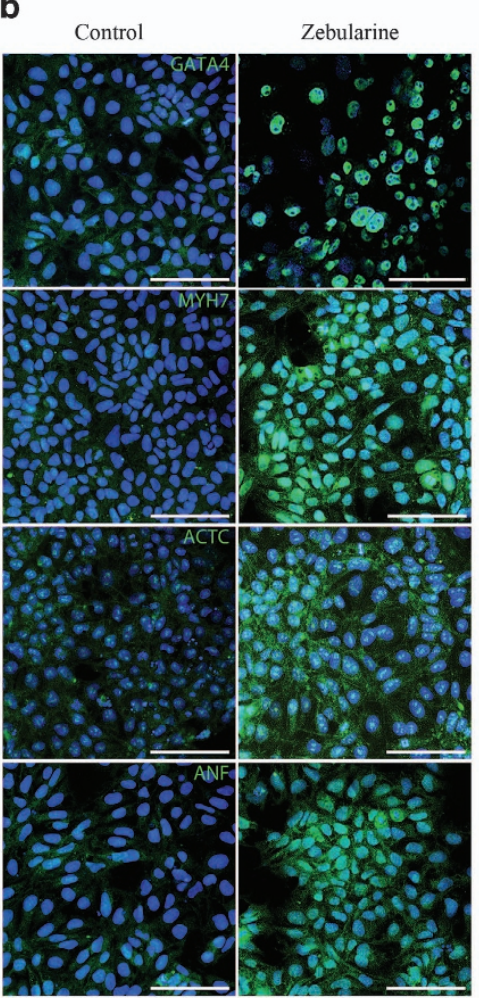

c

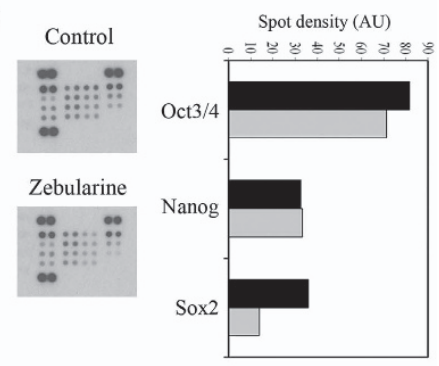

d

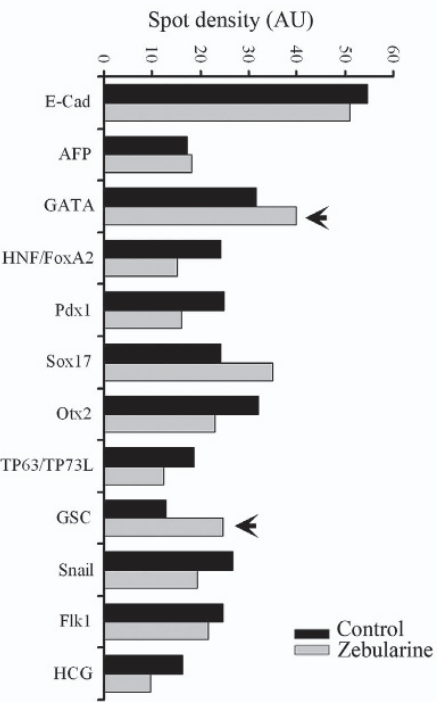

Figure 7 Characterization of HS-181 cell line after treatment with zebularine. (a) RT-PCR of cardiac markers after treatment with zebularine. Myh7, Myh6, Actc, cTnl and Serca2 present more expression after treatment. (b) Immunostaining of treated cells to detect cardiac-specific proteins. Scale bars; $50 \mu \mathrm{m}$. (c) Blots of Proteome Profiler Array and the resulting quantification histograms demonstrating inhibition of pluripotency marker expression and (d) increased levels of mesodermic proteins after zebularine treatment (black arrows)

our knowledge, this is the first time that zebularine has been shown to differentiate ESCs towards cardiac-like cells more efficiently than other tested drugs.

Also, we observed that zebularine addition induced rhythmic and coordinated contractions and the ability to respond to cardiotropic drugs, suggesting that zebularinetreated cells possess cardiac-like functionality.

During cell differentiation, it has been suggested that the accumulation of cell lineage-specific methylation patterns could give rise to tissue-dependent and differentially methylated regions, such as those found in some $\mathrm{CpG}$ islands. ${ }^{34}$ This indicates that promoter methylation of specific genes involved in cellular differentiation may occur and thereby commit cells towards a specific lineage. Analysis of promoter methylation status of some genes involved in pluripotency and cellular differentiation showed that after zebularine administration, Oct3/4 and Nanog were transcriptionally inactivated via DNA methylation, suggesting that these cells would be biased towards differentiation. Meanwhile, the $N k x 2.5$ gene was clearly more activated after zebularine treatment, as its promoter became unmethylated. This indicates that cells treated with zebularine not only decrease the expression of pluripotency markers but also start to express genes that have pivotal roles in cardiac differentiation. In addition, we have demonstrated that zebularine is able to enhance histone $\mathrm{H} 4$ acetylation and modify the activity of HDAC and DNMT, in addition to reducing the methylation of H3K9. Zebularine also enhanced DNA demethylase activity and increased the methylation of H3K4. Hence, these global modifications induced by zebularine open and relax the structure of chromatin, increasing the accessibility of promoters to transcriptional machinery.

It has been recently suggested that DNMTs, in addition to incorporating methyl groups into gene promoter regions, may also enforce gene silencing through the recruitment of transcriptional repressor protein complexes that carry proteins with HDAC activity. ${ }^{35}$ This would create a scenario where DNA methylation is correlated with the compaction of chromatin structure. This suggestion is in concordance with our data that demonstrate a decrease of DNMT activity in conjunction with a decrease in HDAC activity.

Furthermore, using genome-wide expression array and 2D-DIGE protein analyses, we have demonstrated that zebularine strongly modifies gene and protein expression. Interestingly, our microarray data matched existing GEO studies (with a high similarity score). However, further analyses should be performed, at least at the protein level.

Finally, zebularine treatment of hESCs enhanced cardiacrestricted genes and protein expression, although no beating cells were detected. The absence of beating areas could be explained by the fact that zebularine is incorporated into DNA during the $S$ phase of the cell cycle. As the doubling time of 
hESCs is longer than that of mESCs, this would explain why zebularine was less efficient in hESCs than in mESCs. Moreover, a protein array panel demonstrated a quantitative increase in mesoderm markers and a slight decrease in pluripotency markers.

These results provide new mechanistic insights regarding the function of zebularine during early ESC differentiation. The link between zebularine and its epigenetic effects opens a new field of investigation aimed at defining the rules of differentiation processes. Indeed, the possibility of priming normal cells with zebularine ex vivo may represent a strategy to obtain specialized cell populations potentially useful for cell therapy.

\begin{abstract}
Materials and Methods
Cell culture and drug administration. The mouse ESC cell line (ES-D3 (D3); ATCC Number: CRL-1934) was cultured in DMEM (Dulbecco's medium) with $15 \% \mathrm{FBS}, 10 \mathrm{U} / \mathrm{ml}$ penicillin, $10 \mu \mathrm{g} / \mathrm{ml}$ streptomycin, $2 \mathrm{mM}$ glutamine, $10^{-4} \mathrm{M} \beta$ mercaptoethanol, $1 \times$ non-essential amino acids and $10^{3} \mathrm{U} / \mathrm{ml}$ LIF, and then maintained at $37^{\circ} \mathrm{C}$ and $5 \% \mathrm{CO}_{2}$. The drug administration to mESCs was prepared in three different experimental ways: (1) standard culture conditions in presence of LIF to compare the effect of different agents: the cells were divided into control group, NO-treated group, Azad-C-treated group and zebularine-treated group, control cultures ( + LIF) were left untreated and experimental cultures were treated with $1 \mu \mathrm{g} / \mathrm{ml} \mathrm{AzadC}, 100 \mu \mathrm{M}$ of $\mathrm{NO}$ and $30 \mu \mathrm{M}$ of zebularine for 7 days. (2) In vitro differentiation to generate derivatives of the three primary germ layers: EBs were generated using the hanging drop method during 3 days in the absence of LIF, and then plated and incubated for $24 \mathrm{~h}$ in a $10-\mathrm{cm}$ plastic dish in DMEM medium without LIF to adhere, control cultures were left untreated and experimental cultures were treated with $30 \mu \mathrm{M}$ of zebularine for 3,5 and 7 days; in parallel cells cultured in monolayer without LIF and without generating EBs, ( - LIF) were used as negative control. (3) Effect of zebularine on mESC differentiation: EBs were generated as in experimental point 2 and the cells were treated with $30 \mu \mathrm{M}$ of zebularine for 7 days (see Figure 2a).

The human ESC cell line (HS-181) was derived in the Fertility Unit of Karolinska University Hospital, Huddinge at the Karolinska Institute after approval of a project entitled 'Derivation and early differentiation and characterization of hESC lines' by the Karolinska Institute Research Ethics Board South, Drno 454/02. This line was derived from an embryo that could not be used for the infertility treatment of a couple. Both partners of the couple signed a consent form for donation of the embryo for derivation of a possible permanent stem cell line to be used in stem cell research. The HS-181 line is included in the EU hESC registry (http:// www.hescreg.eu/) and cultured as described by Hovatta et al. ${ }^{36}$ To promote differentiation, cells were cultured on Matrigel, bFGF was withdrawn from the medium and cells were subjected to EB formation and $30 \mu \mathrm{M}$ zebularine treatment for 7 days, as described for mESCs.
\end{abstract}

Analysis of apoptosis. Apoptosis was evaluated using an Annexin-V-FITC apoptosis detection kit II (BD Pharmingen, San Diego, CA, USA). Briefly, the cells were divided into Control group, zebularine-treated group and Azad-C-treated group. In each time point (3, 5 and 7 days), cells were trypsinized to prepare a single-cell suspension (detached cells) and centrifuged at $1800 \mathrm{r} / \mathrm{min}$ for $6 \mathrm{~min}$ at $4^{\circ} \mathrm{C}$. Cell pellets were washed two times with cold PBS and then stained with Annexin-V-FITC and propidium iodide (PI), following the manufacturer's instructions. For each sample, FITC-Annexin-V and PI staining were analyzed using Flow Cytometry (BD FACSCalibur cytometry System, San Jose, CA, USA). The data were analyzed using the CellQuest software (BD, San Jose, CA, USA).

Control samples were normalized to 1 . The SPSS statistical package (v. 13.0, SPSS Inc., Chicago, IL, USA) was used for statistical analysis. Data were analyzed for statistical significance using one-way ANOVA and Tukey's B test: an analysis of variance type I (ANOVA I) was used to determine the statistical significance differences between treatments. Once confirmed, Tukey's $B$ discriminatory analysis was performed to determine the existence of significance differences between the groups.

Flow cytometry. Cardiac proteins expression was analyzed by flow cytometry. Briefly, EBs were trypsinized and fixed with $4 \%$ paraformaldehyde. The cells were treated with blocking solution (PBS containing 3\% BSA, $0.1 \%$
Triton X-100), and incubated for $1 \mathrm{~h}$ at $4{ }^{\circ} \mathrm{C}$ with primary anti-Gata4, anti-Actc, antiFlk1, anti-Myh7, anti-sarcomeric Actc, anti-Anf and anti-Desmin. After washing, the cells were incubated for $30 \mathrm{~min}$ with secondary antibodies. Unlabeled cells and cells labeled with secondary antibody were used as controls. The data were analyzed using the CellQuest software to calculate the percentage of positive cells.

RT-PCR analysis. Total RNA was extracted from control and treated cells using TRIzol Reagent (Invitrogen, Carlsbad, CA, USA) following the manufacturer's instructions. RNA concentration was quantified using a NanoDrop spectrophotometer, and $1 \mu \mathrm{g}$ of total RNA was reverse transcribed using MMLV retrotranscriptase (Promega, Madison, WI, USA) and random hexamers.

cDNA was amplified using $0.05 \mathrm{U} / \mu$ l of Eco-Taq polymerase (Ecogen, Barcelona, Spain) and $400 \mathrm{nM}$ of specific primers. In all, 26 amplification cycles were used. Quantitative real-time PCR was performed using SYBR-Green and detected using an ABI Prism 7500 system (Applied Biosystems, Foster City, CA, USA). Primer information is described in Supplementary Table 1.

Western blotting assay. Cells were lysed in RIPA buffer (Sigma-Aldrich, St Louis, MO, USA) complete with protease inhibitors (Roche Diagnostics $\mathrm{GmbH}$, Mannheim, Germany). Protein concentration was quantified by Bradford colorimetric assay (Sigma-Aldrich), and $20 \mu \mathrm{g}$ of proteins were separated using SDS-PAGE, transferred to PDVF membrane and probed with anti- $\beta$-actin (Sigma-Aldrich; A5441), anti-Actc (Santa Cruz Biotechnology, Dallas, TX, USA; SC15335), anti-Gata4 (Abcam, Cambridge, UK; AB4132), anti-Myh7 (Santa Cruz Biotechnology; SC12117), anti-Anf (Abcam; AB5490), anti-cTnT (Abcam; AB10214), anti-Desmin (Sigma-Aldrich; D8281), anti-Flk1 (Millipore, Billerica, MA, USA; 07-716), anti-sarcomeric Actc (Sigma-Aldrich; A7811), anti-acetyl histone H4 (Upstate, Lake Placid, NY, USA; 06-598), antimonomethyl Lys9 H3 (Upstate; 07-450) and anti-trimethyl Lys4 H3 (Upstate; 07-473).

Immunofluorescence staining. Cells were fixed and permeabilized with methanol, incubated at $-20^{\circ} \mathrm{C}$ for $20 \mathrm{~min}$ and blocked with donkey serum in PBS $(\mathrm{pH} 7.4)$, and then labeled with appropriate primary antibodies (1:1000). The primary antibodies used were mostly the same as those used for western blotting, and the secondary antibodies used were Alexa Fluor 488 goat anti-rabbit (Invitrogen; A11034), Alexa Fluor 488 goat anti-mouse (Invitrogen; A11029) and Alexa Fluor 568 donkey anti-goat (Invitrogen; A11057). Digital images were obtained using a Leica SP5 confocal microscope (Leica, Mannheim, Germany) or an Olympus IX71 inverted microscope (Olympus, Tokyo, Japan).

Proteome profile array. Protein expression profiles were assayed using the specific human pluripotent Stem Cell array kit 'Proteome Profiler Array' (R\&D Systems Europe, Abingdon, UK; ARY010) following the manufacturer's instructions. This array allowed us to detect simultaneously 15 different stem cell markers related to pluripotency and differentiation processes. The densitometry analysis of the resulting spots was carried out using the ImageJ 1.41 software (Wayne Rasband, NIH, Bethesda, MD, USA).

Chronotropic drugs treatment. Beating areas of cell culture treated with zebularine were subjected to $2 \mu \mathrm{M}$ isoproterenol, and the frequency of beating was counted 1 and 2 min after treatment. The medium was changed and $50 \mu \mathrm{M}$ diltiazem was added to the cultures, and contractions were counted until they stopped. Movies were captured on Olympus IX71 inverted microscope using Olympus DP70 digital camera system (Olympus) and the Olympus DP Controller software (Olympus).

Bisulfite modification and MSP. Genomic DNA was extracted by phenol-chloroform extraction and purified using the Wizard DNA Clean-up system (Promega). Bisulfite modification was performed using the EZ-DNA Methylationgold kit (Zymo Research Corp., Irvine, CA, USA) following the manufacturer's instructions. Specific primers (Supplementary Table 1) were designed using Methyl Primer Express Software (Applied Biosystems), and MSP was performed as follows: $95^{\circ} \mathrm{C}$ for $3 \mathrm{~min}, 40$ cycles of $95^{\circ} \mathrm{C}$ for $30 \mathrm{~s}, 55^{\circ} \mathrm{C}$ for $1 \mathrm{~min}, 72^{\circ} \mathrm{C}$ for $1 \mathrm{~min}$ and $72{ }^{\circ} \mathrm{C}$ for $7 \mathrm{~min}$. Samples were loaded on a $2 \%$ agarose gel.

Bisulfite sequencing. DNA was isolated using DNeasy kit (Qiagen, Hilden, Germany) from EBs (Control, Zebularine and Azad-C) grown for 7 days to allow differentiation. In all, $1 \mu \mathrm{g}$ of DNA was then bisulphite converted using the Cells-to$\mathrm{CpG}^{\mathrm{M}}$ Bisulfite Conversion kit (Applied Biosystems) according to the manufacturer's recommendation. Methyl Primer Express Software (Applied Biosystems) was 
used to design primers for $\mathrm{CpG}$ islands flanking the same sequence region used for MSP (Supplementary Table 1). Bisulfite-modified DNA was amplified using a ho start Taq polymerase (MyTaq HS Red DNA Polymerase; Bioline Reagents Ltd., London, UK), starting with denaturation at $95^{\circ} \mathrm{C}$ for $5 \mathrm{~min}$, and then 35 cycles of denaturation at $95^{\circ} \mathrm{C}$ for $30 \mathrm{~s}$, annealing at optimal $T_{\mathrm{m}}$ for $15 \mathrm{~s}$, extension at $72^{\circ} \mathrm{C}$ for $15 \mathrm{~s}$, followed by an extra extension at $72^{\circ} \mathrm{C}$ for $10 \mathrm{~min}$. Amplicons were purified using the QIAquick PCR Purification kit (Qiagen) and were cloned in pGEM-T vector at a 3:1 insert:vector molar ratio. DH $5 \alpha$-competent cells (Invitrogen) were transformed by heat shock and grown overnight on LB-agar plates containing ampicillin, X-gal and IPTG. CpG primers described above was used to amplify bisulfite-modified DNA directly from 4 to 10 white colonies; amplicons were then purified enzymatically with ExoSAP-IT (USB, Cleveland, OH, USA) and $50 \mathrm{ng}$ of PCR product were bidirectionally sequenced using the BigDye Terminator v.3.1 Cycle Sequencing kit (Applied Biosystems). Fragments were separated on an ABI3730xl DNA Analyzer (Applied Biosystems) and analyzed with Variant Reporter Software v.1.0 (Applied Biosystems). BiQ Analyzer software (Max-Planck-Institut, Saarbrüken, Germany) was used to analyze methylation patterns and generate diagrams. In all, $1 \mu \mathrm{g}$ of DNA from Control EBs was methylated by MSssl CpG methyltransferase using the recommended protocol (New England Biolabs, Ipswich, MA, USA) and used in parallel with samples as control for bisulfite conversion and sequencing efficiency and accuracy.

Epigenetic enzyme activity analysis. The epigenetic enzyme activity measurements and calculations were performed according to the manufacturer's protocols and formulas. DNMTs activity (Catalog no.: P-3001), HMT activity H3K4 (Catalog no.: P-3002), HMT activity H3K9 (Catalog no.: P-3003) and demethylase activity (Catalog no.: P-3019) were measured using $10 \mu \mathrm{g}$ of nuclear protein extracts in the EpiQuik Kits (Epigentek, Farmingdale, NY, USA). HDAC activity was analyzed using the HDAC Colorimetric Assay Kit (BioVision, Milpitas, CA, USA), and the colorimetric intensity was measured using a Varioskan Flash microplate reader (Thermo Electron, Vantaa, Finland). Nuclear proteins were isolated using the Subcellular Proteome Extraction Kit (Calbiochem, San Diego, USA), and $5 \mu \mathrm{g}$ of extracts were used for this assay.

Microarray analysis. Total RNA was isolated using the RNeasy Mini Kit (Qiagen), and $1 \mu \mathrm{g}$ was used to obtain the gene expression profile of each sample. The signals were quantified using spectrophotometry and verified using a microfluidics-based platform (Genomic core facility of CABIMER). All samples showed the characteristics of high-quality RNA and were subjected to subsequent analysis. cRNA was hybridized on an Affymetrix GeneChip Mouse Genome 4302.0 Array (Affymetrix, Santa Clara, CA, USA). The data presented in this publication have been deposited in NCBl's GEO ${ }^{37}$ and are accessible through GEO Series accession number GSE29072 (http://www.ncbi.nlm.nih.gov/geo/query/acc.cgi?acc=GSE29072). In addition, data were subjected to Gene Ontology analysis and IPA software to determine the possible biological functions and pathways.

2D-DIGE proteomic analysis. Proteins were extracted with $30 \mathrm{mM}$ Tris, $7 \mathrm{M}$ urea, $2 \mathrm{M}$ thiourea and $4 \%$ (w/v) CHAPS, pH 8.0. Cells were then sonicated in a Bioruptor and centrifuged at 12000 r.p.m. at $4{ }^{\circ} \mathrm{C}$ for $10 \mathrm{~min}$. The supernatant was collected, $1 \mu \mathrm{l}$ of TCEP was added and samples were incubated for $30 \mathrm{~min}$ in the dark at $37^{\circ} \mathrm{C}$. Next, Cy3 or Cy 5 dye was added $(2 \mu \mathrm{l})$ and the staining reaction was stopped using $7 \mathrm{M}$ urea, $2 \mathrm{M}$ thiourea, $4 \%$ (w/v) CHAPS, $2 \%$ (v/v) pharmalyte and $130 \mathrm{mM}$ DTT. Proteins were quantified using the Bradford colorimetric assay (Sigma-Aldrich), and 1D electrophoresis was performed with Inmobiline Drystrip pH 3-11 NL, 18-cm strips (GE Healthcare, Buckinghamshire, UK). In all, $5 \mu \mathrm{g}$ of protein were used per strip. The strips were focused in an IPGphor system for $22 \mathrm{~h}$. 2D-PAGE was performed with $10 \%$ duracryl acrylamide gels (Genomics Solutions, Ann Arbor, MI, USA), and electrophoresis was performed using an Ettan Dalt VI system (Amersham, Buckinghamshire, UK) according to the following protocol: $2.5 \mathrm{~W}$ per gel for $30 \mathrm{~min}$, followed by a second step of $12.5 \mathrm{~W}$ per gel for $5 \mathrm{~h}$. Fluorescence was visualized using a Typhoon Trio (Amersham).

Statistical analysis. Values are presented as mean \pm S.D., unless otherwise indicated, statistical significance was calculated using an unpaired Student's $t$-test and $P<0.05$ was considered significantly different.

\section{Conflict of Interest}

The authors declare no conflict of interest.
Acknowledgements. The technical assistance and suggestions of N Mellado and EJ López are greatly appreciated. We thank A Krishan for his help with microarray analysis and $\mathrm{K}$ Kamenarova for her assistance with Sanger (direct) sequencing. We were supported by Fundación Progreso y Salud, Consejería de Salud, Junta de Andalucía (Grant PI-0022/2008); Consejería de Innovación Ciencia y Empresa, Junta de Andalucía (Grant CTS-6505; INP-2011-1615-900000); FEDER co-funded grants from Instituto de Salud Carlos III (RD06/0010/0025; PI10/ 00964) and the Ministry of Health and Consumer Affairs (Advanced Therapies Program Grant TRA-120). CIBERDEM is an initiative of the Instituto de Salud Carlos III. AH was awarded a 'Ramón Areces' postgraduate scholarship.

1. Hmadcha A, Domínguez-Bendala J, Wakeman J, Arredouani M, Soria B. The immune boundaries for stem cell based therapies: problems and prospective solutions. J Cell $\mathrm{Mol}$ Med 2009; 13: 1464-1475

2. Eiges R, Urbach A, Malcov M, Frumkin T, Schwartz T, Amit A et al. Developmental study of fragile $X$ síndrome using human embryonic stem cells derived from preimplantation genetically diagnosed embryos. Cell Stem Cell 2007; 1: 568-577.

3. Dvash T, Ben-Yosef D, Eiges R. Human embryonic stem cells as a powerful tool for studying human embryogenesis. Pediatr Res 2006; 60: 111-117.

4. Pickering SJ, Minger SL, Patel M, Taylor H, Black C, Burns CJ et al. Generation of a human embryonic stem cell line encoding the cystic fibrosis mutation deltaF508, using preimplantation genetic diagnosis. Reprod Biomed Online 2005; 10: 390-397.

5. Verlinsky Y, Strelchenko N, Kukharenko V, Rechitsky S, Verlinsky O, Galat V et al. Human embryonic stem cell lines with genetic disorders. Reprod Biomed Online 2005; 10: 105-110.

6. Festag M, Sehner C, Steinberg P, Viertel B. An in vitro embryotoxicity assay based on the disturbance of the differentiation of murine embryonic stem cells into endothelial cells. I: Establishment of the differentiation protocol. Toxicol In Vitro 2007; 21: 1619-1630.

7. Fico A, Manganelli G, Simeone M, Guido S, Minchiotti G, Filosa S. High-throughput screening-compatible single-step protocol to differentiate embryonic stem cells in neurons. Stem Cells Dev 2008; 17: 573-584.

8. Lagarkova MA, Volchkov PY, Lyakisheva AV, Philonenko ES, Kiselev SL. Diverse epigenetic profile of novel human embryonic stem cell lines. Cell Cycle 2006; 5 : 416-420.

9. Bernstein BE, Mikkelsen TS, Xie X, Kamal M, Huebert DJ, Cuff J et al. A bivalent chromatin structure marks key developmental genes in embryonic stem cells. Cell2006; 125: 315-326.

10. Lee TI, Jenner RG, Boyer LA, Guenther MG, Levine SS, Kumar RM et al. Control of developmental regulators by Polycomb in human embryonic stem cells. Cell 2006; 125 : 301-313.

11. Sparmann A, van Lohuizen M. Polycomb silencers control cell fate, development and cancer. Nat Rev Cancer 2006; 6: 846-856.

12. Marson A, Levine SS, Cole MF, Frampton GM, Brambrink T, Johnstone S et al. Connecting microRNA genes to the core transcriptional regulatory circuitry of embryonic stem cells. Cell 2008; 134: 521-533.

13. Hmadcha A, Bedoya FJ, Sobrino F, Pintado E. Methylation-dependent gene silencing induced by interleukin 1beta via nitric oxide production. J Exp Med 1999; 190: 1595-1604.

14. Papait R, Monti E, Bonapace IM. Novel approaches on epigenetics. Curr Opin Drug Discov Devel 2009; 12: 264-275.

15. Choi SC, Yoon J, Shim WJ, Ro YM, Lim DS. 5-Azacytidine induces cardiac differentiation of P19 embryonic stem cells. Exp Mol Med 2004; 36: 515-523.

16. Yoon BS, Yoo SJ, Lee JE, You S, Lee HT, Yoon HS. Enhanced differentiation of human embryonic stem cells into cardiomyocytes by combining hanging drop culture and 5-azacytidine treatment. Differentiation 2006; 74: 149-159.

17. Marquez VE, Kelley JA, Agbaria R, Ben-Kasus T, Cheng JC, Yoo CB et al. Zebularine: a unique molecule for an epigenetically based strategy in cancer chemotherapy. Ann N Y Acad Sci 2005; 1058: 246-254.

18. Marquez VE, Barchi JJ Jr, Kelley JA, Rao KV, Agbaria R, Ben-Kasus T et al. Zebularine: a unique molecule for an epigenetically based strategy in cancer chemotherapy. The magic of its chemistry and biology. Nucleosides Nucleotides Nucleic Acids 2005; 24: 305-318.

19. Zhou L, Cheng X, Connolly BA, Dickman MJ, Hurd PJ, Hornby DP. Zebularine: a novel DNA methylation inhibitor that forms a covalent complex with DNA methyltransferases. $J$ Mol Biol 2002; 321: 591-599.

20. de Vos D, van Overveld W. Decitabine: a historical review of the development of an epigenetic drug. Ann Hematol 2005; 84(Suppl 1): 3-8; Erratum in: Ann Hematol 2006; 85: 557.

21. Goffin J, Eisenhauer E. DNA methyltransferase inhibitors - state of the art. Ann Oncol 2002; 13: 1699-1716.

22. Yoo CB, Chuang JC, Byun HM, Egger G, Yang AS, Dubeau L et al. Long-term epigenetic therapy with oral zebularine has minimal side effects and prevents intestinal tumors in mice. Cancer Prev Res 2008; 1: 233-240.

23. Ritchie ME, Silver J, Oshlack A, Holmes M, Diyagama D, Holloway A et al. A comparison of background correction methods for two-colour microarrays. Bioinformatics 2007; 23: 2700-2707.

24. Lamb J, Crawford ED, Peck D, Modell JW, Blat IC, Wrobel MJ et al. The Connectivity Map: using gene-expression signatures to connect small molecules, genes, and disease. Science 2006; 313: 1929-1935.

25. Chen K, Wu L, Wang ZZ. Extrinsic regulation of cardiomyocyte differentiation of embryonic stem cells. J Cell Biochem 2008; 104: 119-128. 
26. Riebeling C, Schlechter K, Buesen R, Spielmann H, Luch A, Seiler A. Defined culture medium for stem cell differentiation: applicability of serum-free conditions in the mouse embryonic stem cell test. Toxicol In Vitro 2011; 25: 914-921.

27. Fujiwara M, Yan P, Otsuji TG, Narazaki G, Uosaki H, Fukushima $\mathrm{H}$ et al. Induction and enhancement of cardiac cell differentiation from mouse and human induced pluripotent stem cells with cyclosporin-A. PLoS One 2011; 6: e16734.

28. Kattman SJ, Witty AD, Gagliardi M, Dubois NC, Niapour M, Hotta A et al. Stage-specific optimization of activin/nodal and BMP signaling promotes cardiac differentiation of mouse and human pluripotent stem cell lines. Cell Stem Cell 2011; 8: 228-240.

29. Mujoo K, Sharin VG, Bryan NS, Krumenacker JS, Sloan C, Parveen S et al. Role of nitric oxide signaling components in differentiation of embryonic stem cells into myocardial cells. Proc Natl Acad Sci USA 2008; 105: 18924-18929.

30. Krumenacker JS, Katsuki S, Kots A, Murad F. Differential expression of genes involved in cGMP-dependent nitric oxide signaling in murine embryonic stem (ES) cells and ES cellderived cardiomyocytes. Nitric Oxide 2006; 14: 1-11.

31. Kanno S, Kim PK, Sallam K, Lei J, Billiar TR, Shears LL II. Nitric oxide facilitates cardiomyogenesis in mouse embryonic stem cells. Proc Natl Acad Sci USA 2004; 101: 12277-12281.

32. Liu Y, Song J, Liu W, Wan Y, Chen X, Hu C. Growth and differentiation of rat bone marrow stromal cells: does 5-azacytidine trigger their cardiomyogenic differentiation? Cardiovasc Res 2003; 58: 460-468.

33. Martin-Rendon E, Sweeney D, Lu F, Girdlestone J, Navarrete C, Watt SM. 5-Azacytidinetreated human mesenchymal stem/progenitor cells derived from umbilical cord, cord blood and bone marrow do not generate cardiomyocytes in vitro at high frequencies. Vox Sang 2008; 95: 137-148.

34. Shiota K, Kogo Y, Ohgane J, Imamura T, Urano A, Nishino $\mathrm{K}$ et al. Epigenetic marks by DNA methylation specific to stem, germ and somatic cells in mice. Genes Cells 2002; 7: 961-969.

35. Estève $\mathrm{PO}$, Chin $\mathrm{HG}$, Pradhan $\mathrm{S}$. Human maintenance DNA (cytosine-5)-methyltransferase and p53 modulate expression of p53-repressed promoters. Proc Natl Acad Sci USA 2005; 102: 1000-1005.

36. Hovatta O, Mikkola M, Gertow K, Strömberg AM, Inzunza J, Hreinsson J et al. A culture system using human foreskin fibroblasts as feeder cells allows production of human embryonic stem cells. Hum Reprod 2003; 18: 1404-1409.

37. Edgar R, Domrachev M, Lash AE. Gene Expression Omnibus: NCBI gene expression and hybridization array data repository. Nucleic Acids Res 2002; 30: 207.

(1) () $\Theta$ Cell Death and Disease is an open-access journal published by Nature Publishing Group. This work is licensed under a Creative Commons Attribution-NonCommercialNoDerivs 3.0 Unported License. To view a copy of this license, visit http://creativecommons.org/licenses/by-nc-nd/3.0/

Supplementary Information accompanies this paper on Cell Death and Disease website (http://www.nature.com/cddis) 